\title{
Place-Names on the Moon: A Report
}

\author{
HAMILL KENNY
}

\section{Growing Public Attention}

E

VER SINCE 1957, when the International Geophysical Year began, the moon's place-names have, to some degree, been in the news. ${ }^{1}$ Perhaps the first example of such publicity occurred in November $1958,{ }^{2}$ when newspapers mentioned ALPHONSE, the moon crater where, so Soviet Dr. N. A. Kozyrev believed, ${ }^{3}$ volcanic action had lately taken place. This news, when it was discussed in December, 1958, by the Italian magazine Oggi, ${ }^{4}$ led to the mention not only of ALPHONSE ("Alfonso"), but of ARISTARCHUS ("Aristarco"), ARZACHEL, COPERNICUS ("Copernico"), KEPLER ("Keplero"), PLATO ("Platone"), POSIDONIUS ("Posidonio"), and "Coda del pavone" (Galileo's Cauda Pavonis or Peacock's Tail). Then in September, $1959,{ }^{5}$ came press notice of three of the moon's "seas": MARE SERENITATIS (Sea of Serenity), MARE TRANQUILLITATIS (Sea of Tranquillity), and the MARE VAPORUM

Symbols and abbreviations: * = Earlier name, now either changed or deleted; I. A. U. = International Astronomical Union; Kuiper = Photographic Lunar Atlas; $\mathrm{LAC}=$ U. S. Air Force Chart; Memoir = "Who's Who in the Moon"; Pamphlet = pamphlet accompaniying Photographic Lunar Atlas.

1 Public attention was attracted to the moon's place-names in the times of Jules Verne (c 1865), when Verne in chs. 12, 13, 17, and 18 of Around the Moon (English version by Mercier and King, 1947), using Beer and Mädler's Mappa Selenographica, has his moon voyagers mention and fictitiously describe thirty-one lunar features, including "Mount Helicon," "Gulf of Iris," "the Black Lake or Pluto," "the annular mountain of Short," and "the circle of Neander."

2, 3 Nov. 3, 1958 (see W. L. Lawrence, N. Y. Times, Jan. 25, 1959). Dr. Kozyrev's report: AP, Moscow, Nov. 13, 1958; N. Y. T., Nov. 13, 1958.

4 "Nella Coda del Pavone Un Nuova Enigma Lunare," Oggi, Dec. 4, 1958, pp. $43-44$.

5 Lunik II was launched Sept. 12, 1959 (Compton's Encyc.; N. Y. T., April 3, 1963). It struck Sept. 13, 1959 (World Bk. Encyc., Ann. Supplement, 1960; N. Y. T., Oct. 1959). World Bk. Encyc., 1961, and AP (Wash. Star), Moscow, April 2, 1963, both give the date of striking as Sept. 14, 1959. 
(Sea of Vapors). ${ }^{6}$ For it was near these "seas," on September 13, that Lunik II struck the moon. ${ }^{7}$ Little more than two years later in $1962,{ }^{8}$ a flash of light activated by a ruby laser also struck the moon, an event that led to public mention of the crater ALBATEGNIUS. On January 13, 1962, in a discussion of ideal moon sites, the press ${ }^{9}$ noticed the LEIBNITZ MTS. ("Leibnitz mountain range"). The same year, a second Italian magazine, Incom, ${ }^{10}$ in a feature article on the moon, spoke of RHAETICUS ("Retico"), SCHICKARD, PHOCYCLIDES ("Focilide"), ERATOSTHENES ("Eratostene"), PLATO ("Platone"), and the APENNINES ("Appennini lunari," "Appennini seleniti"). Scanty as they are, such instances suggest on the part of the public an increasing acquaintance with the moon's place-names.

\section{Need for Lunar Place-Names}

Astronomers need these place-names to enable them to refer to and discuss the moon's visible features. Eppa Loretta ${ }^{11}$ declares: "If the craters or the seas had no names, the study of them would be practically impossible..." New lunar features are, of course, continually being identified. Moreover, the possibility that the moon may be visited makes it likely that our satellite, from the standpoint of its place-names, will soon cease to be merely "le cimetiere des astronomes et la Pantheon des savants." 12

6 N. Y. T., Sept. 14, 1959, and Compton's Encyc. (1962) have Seas of Tranquillity, Serenity and Vapors, and Maria Serenitatis, Tranquillitatis, and Vaporum, respectively. The Washington Post (Sept. 15, 1959), and lately the N. Y. Times (April 3, 1963) have, respectively, Seas of Tranquillity, Vapors and Clarity, and Seas of Clarity, Serenity, and Vapors. Thus, the Post translates MARE SERENITATIS as "Sea of Clarity"; and the Times translates MARE TRANQUILLITATIS as "Sea of Clarity." So far as I know, astronomers do not recognize "Sea of Clarity" for either.

7 See 5 and 6.

8 Stuart H. Loory, “The Incredible Laser...," This Week Magazine, Nov. 11, 1962, p. 8.

9 The Washington Star.

10 Anno XV, N. 47 (Nov. 25, 1962), pp. 40-43, p. 45.

11 "Proposal for Naming the Rays of the Lunar Craters," Popular Astronomy, 43, No. 1 (January 1935).

12 Abbé Moreux, Etude de la Lune avec Dictionnaire Selenographique, Nouvelle Ed. (Paris, 1950), p. 45. 


\section{History of Lunar Place-Names}

"Who's Who in the Moon"13 gives a history of lunar place-names, and contains explanatory and biographical notes on the names of all the formations adopted in 1935 by the I.A.U. For "I.A.U." and the like see Symbols and abbreviations preceding footnote 1 on $p$. 73. The Memoir points out that Langrenus of Brussels (Map, 1645) first gave names to the moon's features, and that the names on a Paris copy of his map come to more than 300 . On the map (Selenographia, 1647) of Johann Hevelius of Danzig, whom Agnes Mary Clerke calls the founder of lunar topography, ${ }^{14}$ the named features number 250 . Departing from the method of Hevelius, Riccioli of Bologna (Almagestum Novum, 1651) named lunar features not only for contemporary astronomers, but also for astronomers of the Middle Ages and antiquity. He lists about 236 features named for persons (e.g., ARISTOTELES), and about seventy-eight features, mainly geographical, which are named impersonally (e.g., *PALUS HYPERBOREA, *TERRA SAPIENTIAE). Riccioli kept Kepler's idea ${ }^{15}$ of the moon's maria or "seas"; but he gave them names that describe the moon's supposed influences on the earth (e.g., MARE CRISIUM, MARE IMBRIUM, and MARE NUBIUM). Moreover, Riccioli had a system: he named the northern lunar features for the ancients (e.g., PLATO); the moderns he put below. Since - as a Jesuit - he disbelieved in the Copernican theory, he gave to an important southern feature the name TYCHO, and relegated the names of the Copernicans to features situated in the OCEANUS PROCELLARUM (Sea of Storms). As for later innovators, Johann Schröter (Selenotopographische Fragmente..., 2 v., 1791, 1802) first began the use of Greek and Roman letters to identify minor lunar formations.

\section{Present Status, Visible Side}

Noting that today's lunar maps keep six of Hevelius' names (e.g., ALPS, APENNINES), and more than 200 of Riccioli's, "Who's

13 "Who's Who in the Moon," Memoirs of the British Astronomical Association (Edinburgh, 1938), 34, Pt. I. The work is definitive and makes further biographical study largely superfluous.

14 "Johann Hevelius," Eleventh Britannica, 13.416.

15 See Clyde Fisher, Story of the Moon (N. Y., 1943), p. 104. He states (loc. cit.): "Possibly ... 'Maria' ... goes back to Kepler (1571-1630), who wrote 'Do maculos esse maria, do lucidas esse terras'." 
Who in the Moon" (p. 5) states that "an authoritative list" of the moon's named formations amounts to 672 , of which 609 are personal names. The Memoir bases its figures on what it calls "our latest standard work," Mary A. Blagg and K. Müller's Named Lunar Formations, ${ }^{16}$ which lists the lunar names drawn up for Commission 17 and approved at a meeting of the I. A. U. in 1932, at Cambridge, Massachusetts. Gerard P. Kuiper ${ }^{17}$ describes the 1935 I. A. U. system as having 680 named formations and some 8000 additional features "with letters and symbols ... regionally attached to named features..." This is, of course, the nomenclature ${ }^{18}$ of the two latest definitive lunar guides, one of which (Photographic Lunar Atlas) has been called "the first complete lunar atlas since 1910,"19 and the other of which (U. S. Air Force Lunar Charts and Mosaics [Charts of the Moon]) began appearing in 1962 and, upon completion, will consist of eighty-four detailed maps.

The Photographic Lunar Atlas omits the alphabetical symbols of the 1935 I. A. U. system. Instead of printing lunar names on its photographs, it divides the moon into forty-four sections and provides index maps (sheets 1-11) and a reference list ("Pamphlet," Table V, pp. 19-23) of the moon's numbered and named formations. On the eighty-four Air Force Lunar Charts and Mosaics (Charts of the Moon), being published, ${ }^{20}$ both the major names and the names of lettered formations are given. Here, as with Kuiper, the moon is

16 (London, 1935). See also Mary A. Blagg, ... Collated List of Lunar Formations Named or Lettered in the Maps of Neison, Schmidt, and Mädler ... (Edinburgh, 1913).

17 ... ed., Photographic Lunar Atlas Based on Photographs Taken at the Mount Wilson, Lick, Pic du Midi, McDonald, and Yerkes Observatories. . . (Chicago [1960]). 23 p. tables (pamphlet $28 \mathrm{~cm}$.) and atlas of 230 photographs ... Pamphlet, p. 6 .

Dr. Kuiper has since edited two supplements: (1) OrthographicAtlas of the Moon. Supplement No. 1 - to the Photographic Lunar Atlas. Edition A, ... Tucson, 1960 to 61 (... Chiefly photos); and (2) Orthographic Atlas of the Moon, Supplement No. 1 to the Photographic Lunar Atlas. Edition B, ... Tucson, 1961. Chiefly photos.

18 Complemented by resolutions and decisions published in the Transactions of the I. A. U. (1950: 7, 63, 160, 166, 169; 1952: 8, 216; 1955: 9, 263), and revised by Gerard Peter Kuiper (see Pamphlet).

19 Folder describing Photographic Lunar Atlas, Univ. of Chicago Press.

20 They are being published by the Aeronautical Chart and Information Center, U. S. Air Force, St. Louis 18. In Jan. 1962, Charts LAC 58 and 76 were available. LAC's $57,59,60,61,74,75,77,78,79,93,94$ were planned for 1962 . LAC 61 was completed on March 22, 1963. LAC's 78, 59, 79, 77, and 56 were to be printed by July 1 , 1963. 
divided into sections, and two "reference mosaics" and a lunar chart index are included. On the Air Force Charts not all of the I. A. U. 1935 standard lunar features are identified. "Eminences" are marked by Greek letters (see LAC 94, May, 1964); Rima is used for Rille. Following Blagg and Müller's system, the Charts utilize capital letters to designate the names of major craters (e.g., COPERNICUS). Smaller neighboring formations, when designated, have lettered names in lower-case letters, with the identifying letters usually single and capitalized (e.g., Copernicus A). ${ }^{21}$ In some instances adjacent formations are given two alphabetical letters, with the second letter not always capitalized (e.g., Copernicus BA; but Grimaldi Ga). ${ }^{22}$ In these lettered names each part has a meaning Copernicus BA, for instance, denotes a crater (A) near another crater (B), the latter itself near the major crater COPERNICUS.

The Photographic Lunar Atlas (see Table III, "Pamphlet") makes the following seventy-one changes in the I. A. U. 1935 list: (1) there are forty-five changes in spelling and typography - ALTAI SCARP is changed from *ALTAI MTS., because it is a scarp, not a mountain; (2) Cleft is replaced by Rille, because Cleft implies cleavage *HYGINUS CLEFT becomes HYGINUS RILLE; (3) thirteen names are deleted - ROOK MOUNTAINS, for instance, because they are on the moon's edge and are not "readily identifiable"; (4) DESLANDRES ${ }^{23}$ has been added - the only name that has lately been recognized by the I. A. U. and added to the 1935 list; (5) *HENRY (FRERES) has, for clarity, been replaced by HENRY, PAUL and HENRY, PROSPER; (6) the boundaries of five named features have been changed - e.g., *WILKINS, a small 'bay,' is no longer included; and (7) five names are used that are not explicit on the I. A. U. map, but are identifiable from their respective original authorities - e.g., WOLFF (MT.), identifiable from Schröter. These changes have been adopted by the U. S. Air Force Charts, which were prepared with the advisory assistance of Dr. Kuiper and the staff of the Photographic Lunar Atlas. However, the Air

21 This is not invariable. The lettered formations near the crater WICHMANN (LETRONNE LAC 75) have, for example, single letters, uncapitalized: Wichmann a, Wichmann b, Wichmann c, and Wichmann d.

22 Air Force Charts COPERNICUS LAC 58, GRIMALDI LAC 74.

${ }^{23}$ Henri Alexandre Deslandres (1853-1948), French physicist and astrophysicist, noted for his contributions to spectroscopy and solar physics. 
Force Charts (see LAC 58, COPERNICUS, July 1961) add to the I. A. U. list thirty-two new lettered formations, ranging from Copernicus $\mathrm{A}, \mathrm{J}$, and $\mathrm{R}$, to Tobias Mayer M, N, T, and S.

\section{Present Status, Hidden Side}

Probable the liveliest single event ever to attract public attention to the moon's place-names was the photographic achievement of Russia's Lunik III in October 1959. ${ }^{24}$ Decked out with brand new place-names, Lunik's snapshots of the moon's hidden side soon appeared in American newspapers. The Washington Star ${ }^{25}$ gave these names as MOSCOW SEA, ASTRONAUTS BAY, TZIOLKOVSKY HILL, LOMONSOV HILL, JOLIOT-CURIE CRATER, SOVIETSKY MOUNTAIN RANGE, and DREAM SEA. The New York Times, three weeks after the feat, ${ }^{26}$ told of a photograph with eight spots named by the Soviet Sciences Academy, including a spot called "Moscow Sea." And on March 19, 1960, the New York Times described the new nomenclature as celebrating T. A. Edison and eleven others, including four Russians. The map of the moon's hidden side in Compton's Encyclopedia ${ }^{27}$ seems, among those in reference books, to have the fullest number of the new Russian names: EDISON CRATER, GIORDANO BRUNO CRATER, HERTZ CRATER, ${ }^{28}$ JOLIOT-CURIE CRATER, ${ }^{29}$ KURCHATOV CRATER, ${ }^{30}$ LOMONSOV CRATER, ${ }^{31}$ MENDELEEV CRATER, ${ }^{32}$

${ }^{24}$ Launched Oct. 4, 1959 (World Bk. Encyclopedia, Ann. Suppl., 1960). Photograph released: N. Y. Times, Oct. 27, 1959; Wash. Star, Oct. 27, 1959. Russian stamp with map of hidden face: N. Y. Times, May 3, 1960.

25 "Moon Pictures Herald Planet Study ...," Oct. 27, 1959.

26 Oct. 27, 1959.

27 1962, vol. 9, p. 482.

28 Richard B. Rodman, translator of An Atlas of the Moon's Far Side, informs me that the man honored by this name is Heinrich Rudolph Hertz (1857-94), who studied electromagnetic transmission and developed Faraday's electromagnetic theory of light.

29 French nuclear scientist. Frederic and Irene Joliot-Curie discovered artificial radioactivity in 1934 .

30 Igor Vasilievich Kurchatov (1903-60), Russian physicist.

31 Mikhail Lomonsov, believed in Russia to have developed the first working model of a helicopter.

32 Dmitri Iranovich Mendeleeff (1834-1907), Russian chemist notable for his researches on the Periodic Law. 
PASTEUR CRATER, POPOV CRATER, ${ }^{33}$ SKLODOWSKACURIE CRATER, ${ }^{34}$ TSU-CHUNG-CHI CRATER, ${ }^{35}$ JULES VERNE CRATER, SEA OF MOSCOW, BAY OF ASTRONAUTS ${ }^{36}$ SOVIET MTS., and SEA OF DREAMS. ${ }^{37}$

In November, 1960, the Associated Press told of the publication of a Soviet Atlas of the far side of the moon, containing thirty pictures and identifying 500 objects. ${ }^{38}$ This atlas, translated by Richard B. Rodman, and entitled An Atlas of the Moon's Far Side; the Lunik III Reconnaissance, ${ }^{39}$ appeared in the United States in 1961. The photographs in the atlas occasionally overlapped the historic lunar features. Therefore there still is some use of the I. A. U. nomenclature (with Kuiper's amendments). For names not yet certified by the I. A. U., the terminology of H. P. Wilkins was adopted. "Pending IAU decision," the names of the newly charted maria, or "seas," have been kept in non-Latinized form (e.g., SEA OF MOSCOW). One gathers from the Index of the Rodman atlas (p. 143) that - in addition to the seventeen new names given in Compton's Encyclopedia (see above) - the Russians named two more new features: LOBACHEVSKY ${ }^{40}$ and MAXWELL (Clerk Maxwell, Brit. physicist, 1831-79). The entire list of the formations photographed by Lunik III is serially numbered on pp. 31-141 and amounts to 498 .

${ }^{33}$ R. Aleksandr Stepanovich Popov (1859-1906), Russian engineer and experimentalist, credited in Russia with the invention of radio.

34 Marja (Marie) Sklodowska Curie (1867-1934), Polish physical chemist and physicist.

35 Tsu Ch'ung - chih, Chinese mathematician and astronomer (430-500), a reviser of the calendar.

${ }^{36}$ Cf. the extinct *MARE ASTRONOMORUM, now MARE FRIGORIS, on the visible side.

${ }^{37}$ Cf. LACUS SOMNIORUM (Lake of Dreams) and PALUS SOMNI (Marsh of Sleep), both on the visible side. The Wash. Star (Oct. 27, 1959) describes the Russian feature as "a so-called sea" on "the very edge of the moon's hidden side, called 'Mechta' (dream)."

38 Wash. Star, Nov. 16, 1960.

39 Akademiia Nauk SSSR ... Editorial board: N. P. Barabashov, A. A. Mikhailov and Yu. N. Lipsky ... New York, ... 1961 vii, 147 p., 30 photographs; loose end map of the Far Side...

40 Nikolai Ivanovich Lobachevski (1793-1856), Russian mathematician. He contributed to the theory of non-Euclidean geometry, and made geometric researches on the theory of parallels. 


\section{Conclusion}

Upon studying the moon's place-names the layman is struck by the fact that many of them are misnomers (SINUS IRIDUM, PALUS SOMNI, LACUS MORTIS, MARE NUBIUM, OCEANUS PROCELLARUM). He notes that the crater names, most of them personal, ${ }^{41}$ do not always do justice to their namesakes - NEWTON, on the moon's limb, is almost invisible, whereas ARISTARCHUS is the moon's brightest crater. ${ }^{42}$ The layman notices, besides, that some of the crater names (ATLAS, HERCULES, HELICON, even PLATO) have little practical lunar connection. He may feel, indeed, that historical lunar nomenclature is neither very scientific nor very appropriate. ${ }^{43}$

Astronomers themselves have now and then shown dissatisfaction with the moon's place-names. *MARE ASTRONOMORUM (Langrenus) has become MARE FRIGORIS, both of them misnomers. ${ }^{44}$ *PHILIP IV has become OCEANUS PROCELLARUM; and *PONTUS EUXINUS (Hevelius) has become the MARIA TRANQUILLITATIS and SERENITATIS. Dr. Kuiper's recent amendments to the I. A. U. nomenclature amount to about seventy-six. In 1955, Commission 16, of the I. A. U., decided to withhold official recognition of all new lunar place-names - until, at least, the completion of "the proposed photographic map of the Moon."

A fault of the present system, Dr. Kuiper suggests, is that there are continual proposals to add the names of contemporary scientists to the crater names. In May, 1955, for example, it was urged that a

41 The moon's most misleading personal place-name is probably HELL, for Father Maximilian Hell (1720-92), Hungarian Jesuit and astronomer. Owen J. Gingerich (Collier's Encyc., 1962, 16: "Moon") seems to refer to this crater when he remarks that the moon's craters "range in size from 150 miles for Bailly, Janssen, Hellplain, Grimaldi, and Clavius, to a few hundred feet."

42 This memorial to Aristarchus is more suitable, however, than one at first realizes. For he appears to have been the first astronomer (Samos, 250 B. C.) to perceive that the earth moves around the sun.

43 One of the more appropriate lunar place-names is HARBINGER MOUNTAINS. Citing Dr. Joseph Ashbrook, Cecilia Payne-Gaposchkin - Professor of Astronomy, Harvard University - informs me (letter, April 16, 1959) that W. Birt gave the name in England in about 1865. The sun's rays reach the Harbinger Mountains before they rise on Aristarchus. The Harbinger Mountains are therefore the harbingers of "the approaching visibility of Aristarchus."

${ }^{44}$ MARE is certainly a misnomer, since evidently the moon has no real seas. 
crater near NEWTON be named for Albert Einstein. ${ }^{45}$ However, says Dr. Kuiper: 'The current 'historical' system ... has acquired some value because many careful observations have been described in its terms."

By commemorating scientists, and by conforming to the fiction of the moon's oceans by such names as SEA OF MOSCOW and BAY OF ASTRONAUTS, the Russians have followed the traditional pattern of the I. A. U. 1935 system. Dr. Kuiper ("Pamphlet," p. 7) states, however, that "in the face of modern requirements" the I. A. U. will soon probably wish to "re-examine the entire problem of lunar nomenclature..." It seems to the present writer that the real worth of the traditional system will get its fullest test when the moon is actually visited, a date that has been estimated to be perhaps $1980 .{ }^{46}$

University of Maryland

Hamill Kenny

45 Meir H. Degani, Astronomy Made Simple (New York, 1955), p. 150.

46 AP, Wash. Star (dateline Philadelphia), Dec. 26, 1959. A later item in this paper ("Moon Map-Guide for a Lunar Landing," Sun., April 21, 1963) states that the area to be visited will probably be OCEANUS PROCELLARUM (Ocean of Storms), where there are the three easily recognized craters, KEPLER, ENCKE, and KUNOWSKY.

\section{ADDENDUM}

Meanwhile, as this article goes to press, a new wave of lunar enthusiam has arisen. I refer to interest in the successful United States space vehicle, Ranger VII, which took close-range photographs and struck the moon's surface on July 31, 1964. On this occasion the lunar place-name most mentioned was MARE NUBIUM, the name of the zone where Ranger VII landed. 